\title{
Mental Health among Entrepreneurs: The Benefits of Consciousness
}

\author{
Jeffrey Overall \\ Ontario Tech University, Canada
}

\begin{abstract}
High enterprise failure rates, the need to pivot, and fleeting runways are contributing to mental health issues among entrepreneurs. To treat a myriad of mental health conditions, western medical practitioners are acknowledging the effectiveness of consciousness and mindfulness tools, like yoga and meditation that have been practiced by indigenous people and eastern cultures for millennia. Some entrepreneurs are starting to use consciousness practices as not only a tool to balance the mind-body connection, but they are also using them to optimize performance. Implications for practice are discussed.
\end{abstract}

Keywords: Consciousness; entrepreneurship; meditation; mental health; mindfulness

Since the 1950s, the rates of depression have increased by $1,500 \%$. In Canada, with a population of nearly 37 million, 500,000 Canadians call into work sick every week due to mental health. This costs the Canadian economy $\$ 20$ billion annually with $\$ 6$ billion of this being directly shouldered by organizations through a lack of productivity. With these figures, some are 
suggesting that modern society is in the midst of a mental health crisis (Overall, 2020).

Although entrepreneurs are often praised for their high quality-of-life and standard of living (Kautonen et al., 2017), with entrepreneurial failure rates close to $80 \%$ (Overall, 2016), the life of the entrepreneur can be stressful. Compared to the general public, entrepreneurs are 50\% more likely to suffer from a mental health condition. They are two times more likely to suffer from depression, six times more likely to suffer from ADHD, three times more likely to suffer from substance abuse, two times more likely to have suicidal thoughts, ten times more likely to suffer from bipolar disorder, and two times more likely to require psychiatric hospitalization (Freeman et al., 2015).

To address the mental health crisis, medical practitioners in western societies are beginning to explore alternative methods, like mindfulness and consciousness practices, such as yoga and meditation. They are observing that, through regular consciousness practices, patients are able to alleviate deep-rooted stresses, trauma, and anxiety. Research has shown that regular consciousness practices are having a profound improvement on mental health (Overall, 2020). As a result of these findings, medical practitioners are increasingly prescribing consciousness practices in their treatment plans (Lavretsky, 2010).

\section{MAIN ARUGMENT}

Consciousness practices have been integral to ancient indigenous wisdom and eastern philosophical traditions, like Buddhism, Taoism, and yoga for millennia. In various eastern traditions, health is synonymous with balancing the mind, body, emotion, and spirit that occurs naturally by enhancing one's consciousness (Cashwell, 2007). Within the past century, however, many of these ancient conversations have entered the scientific lexicon starting with the work of Emerson, Thoreau, and Whitman among others (Coholic, 2005).

Consciousness practices have been shown to aid in remedying various ailments such as: chronic pain, Axis I disorders, fibromyalgia, and cancer-related mood disturbances (Vlasic, 2013; Lavretsky, 2010). Through regular practice, individuals are able to achieve a profound state of relaxation that simultaneously alleviates deep-rooted stresses and anxiety (Alexander et al., 1991). Medical practitioners have used consciousness practices as part of psychotherapeutic treatments designed to help emergency personnel better manage, cope with, and overcome post-traumatic stress disorder (PTSD) (Godwin, 2018). In addition to stress, consciousness practices are used to treat anxiety, depression, and to assist those with overcoming addiction (Sultanoff, 2002). Given that stress is one of the leading causes of health deterioration, 
Lim (2018) has shown that a consciousness regime can help improve serious health conditions, like: diabetes, heart disease, and cancer. Practitioners have showed significant improvements in attentional performance, cognitive flexibility, and cognitive functions on all levels of attention (Moore \& Malinowski, 2009). Even in the midst of transitioning through difficult times, sustaining a consciousness regime can help people maintain a healthy mindbody connection (Freeman, 1998).

For entrepreneurs, consciousness practices have been shown to aid in enhancing their: interpersonal skills, emotional self-awareness, and ability to self-actualize. This helps them manage their stress and emotional reactions. Through regular practice, leaders become more vulnerable, genuine, congruent, balanced, and authentic in their interactions (Purnell-Webb et al., 2002). When this enhanced authenticity is integrated throughout the organizational hierarchy, managers are better able to engage with their subordinates by developing deeper interpersonal relationships, which translates into improved leadership capabilities (Young, 2002) whereby managers are in a better position to rally their subordinates, develop motivational, and inspirational abilities. In turn, they are better able to perform at their optimal level (Amar et al., 2015). Through regular practice, entrepreneurs are able to increase: imagination, visualization, sensing, feeling, focusing (Sultanoff, 2002), creativity, and innovation. To this end, entrepreneurs are using consciousness practices as a tool to optimize performance.

Given the benefits, multinational organizations like The Body Shop and Tom's of Maine, have started integrating consciousness practices within their strategic plans (Purnell-Webb et al., 2002). The leadership of Whole Foods and LinkedIn are using consciousness terminology. Xerox, Pizza Hut, and Taco Bell have started investing in the mind-body connection of their employees by offering them incentives. Google has installed meditation centres in their corporate campuses and other companies, like Deloitte, offer onsite yoga sessions for employees. PwC has also implemented various wellness programs that incentivize employees to focus on enhancing their mind-body connection through physical, emotional, mental, and spiritual wellbeing, which has led to significant improvements in employee morale and wellness (LaVito, 2018).

\section{CONCLUSIONS/ IMPLICATIONS}

Resources have been put toward aiding entrepreneurs and entrepreneurship students in overcoming the entrepreneurial failure rates (Overall et al., 2018). However, an equal amount of resources have not been spent on aiding 
entrepreneurs in coping with the mental health challenges of entrepreneurship. To this end, it is recommended that policy makers and entrepreneurship educators promote the benefits of consciousness practices to entrepreneurs to better equip them with the skills needed to succeed. Entrepreneurs need to be given the road map so that they know how to navigate their internal challenges. Beyond the performance optimization that can be gained through consciousness practices, these tools are lifesaving strategies (Overall, 2020).

\section{REFERENCES}

Alexander, C.N., Rainforth, M.V., \& Gelderloos, P. (1991). Transcendental meditation, self-actualization, and psychological health: A conceptual overview and statistical meta-analysis. Journal of Social Behavior and Personality, 6(5), 189-249.

Amar, A., Hlupic, V. \& Tamwatin, T. (2015). Effects of Practicing Meditation in the East and the West: Leaders in the West Benefit More. Academy of Management Conference 2015, Vancouver, Canada. https://westminsterresearch.westminster.ac.uk/item/q28v7/effects-ofpracticing-meditation-in-the-east-and-the-west-leaders-in-the-westbenefit-more

Cashwell, C. S., Bentley, D. P., \& Yarborough, P. (2007). The only way out is through: The peril of spiritual bypass. Counseling and Values, 51, 139148.

Coholic, D. (2005). The helpfulness of spiritually influenced group work in developing self-awareness and self-esteem: A preliminary investigation. The Scientific World Journal, 5(2005), 789-802.

Godwin, R. (2018, August 4). You've had what we call a cosmic orgasm: The rise of conscious breathing. The Guardian. https://www.theguardian.com/lifeandstyle/2018/aug/04/cosmicorgasm-rise-of-conscious-breathing

Freeman, M.A., Johnson, S.L., Staudenmaier, P.J., \& Zisser, M.R. (2015). Are entrepreneurs "touched with fire"? University of California San Francisco. https://michaelafreemanmd.com/Research.html

Freeman, A. (1998). Spirituality, well-being, and ministry. The Journal of Pastoral Care, 52(1), 7-18.

Kautonen, T., Kibler, E., \& Minniti, M. (2017). Late-career entrepreneurship, income and quality of life. Journal of Business Venturing, 32(3), 318333. 
LaVito, A. (2018, September 26) Anxiety is expensive: Employee mental health costs rise twice as fast as all other medical expenses. Health and Science. CNBC. https://www.cnbc.com/2018/09/26/employers-are-starting-tothink-about-healthy-differently.html

Lavretsky, H. (2010). Spirituality and aging. Aging Health, 6(6), 749-769.

Lim, J.R. (2018, May 29) Mindful medicine. Can meditation really cure disease? Men's Journal. https://www.mensjournal.com/health-fitness/howmindfulness-meditation-can-cure-disease-w446104/

Moore, A., \& Malinowski, P. (2009). Meditation, mindfulness and cognitive flexibility. Consciousness and Cognition, 18, 176-186.

Overall, J.S. (2016). The dark side of entrepreneurship: A conceptual framework of cognitive biases, neutralization, and risky entrepreneurial behaviour. Academy of Entrepreneurship Journal, 22(2), 1-12.

Overall, J.S. (2020). The pursuit of sustainable happiness. Ivey Business Journal. https://iveybusinessjournal.com/the-pursuit-of-sustainable-happiness/

Overall, J.S. Gedeon, S., \& Valliere, D. (2018). What can universities do to promote entrepreneurial intent? International Journal of Entrepreneurial Venturing, 10(3), 312-332.

Purnell-Webb, P., Glendon, I., \& Creed, P. (2002). Understanding spirituality in the workplace: A qualitative study. Journal of Spirituality, Leadership and Management, 2002(1), 2-14.

Sultanoff, B.A. (2002). Chapter 10 - breath work. Handbook of complementary and alternative therapies in mental health. ScienceDirect, 209-227.

Vlasic, R.L. (2013). Waking up: Radical self-change through mindfulness and spirituality. [Ph.D. Thesis. Michigan School of Professional Psychology]. ProQuest Dissertations Publishing. https://search.proquest.com/openview/4baa17f7f4f45cdbfa43b41e1b2e 1211/1?pq-origsite $=$ gscholar \&cbl $=18750 \&$ diss $=y$

Young, J.E. (2002). A spectrum of consciousness for CEOs: A business application of Ken Wilber's spectrum of consciousness. The International Journal of Organizational Analysis, 10(1), pp. 30-54.

JEFFREY OVERALL, $\mathrm{PhD}$, is an associate professor of entrepreneurship and strategy at Ontario Tech University. He is an expert researcher in conscious business where he studies the link between consciousness (mindfulness) and: optimum performance, increased productivity, sustainability, and financial performance.

Email: jeffrey.overall@ontariotechu.ca 